\title{
Study of association and correlation of cardio-metabolic risk in diabetics and hypertensive patients with established anthropometric surrogate
}

\author{
Nidhi D Sinha' ${ }^{1}$ B.N. Mishra ${ }^{2, *}$, S.C Mohapatra ${ }^{3}$ \\ ${ }^{\mathbf{1}}$ Associate Professor, ${ }^{\mathbf{2}}$ Professor, ${ }^{\mathbf{3}}$ Dean Academics \& Professor, ${ }^{\mathbf{1}}$ Dept. of Dental, ${ }^{\mathbf{2}, \mathbf{3}}$ Dept. of Community Medicine, ${ }^{\mathbf{1}, \mathbf{2}} \mathrm{R}$. D. Gardi Medical \\ College. Ujjain, Madhya Pradesh, ${ }^{3}$ SGT University, Gurugram, Haryana, India \\ *Corresponding Author: B.N. Mishra \\ Email: badrinmishra@gmail.com
}

\begin{abstract}
The pandemic of essential hypertension, obesity, Type 2 diabetes, and there associate dislipidemia (HOD complex) have set a new benchmark in disease epidemiology. ${ }^{1-3}$ Their concordance is magnanimous and multifaceted but not universal. Thus the need arises to explore their geo-cultural associates.

Aim: This cross sectional study explored this dimension for rural Indian inpatients in a Central Indian tertiary healthcare facility. Established anthropometric tools are explored for their association with the HOD complex in order to shortlist the valued ones.

Result: BMI (body mass index) and WC (waist circumference) were found to be strong associates with HTN (essential hypertension) $\left(\mathrm{X}^{2}=\right.$ 0.0034 d.f $=1, \mathrm{P}<0.001$ ). Type $2 \mathrm{DM}$ (diabetes Mellitus) showed strong association with positive family history $(\chi 2$ value 8.47 d.f $=1$ $\mathrm{p}=0.003$ ). Risky vices like smoking, alcohol consumption, high fat and sugar diet, and lack of exercise had a pretty strong association with HOD complex as a whole ( $\chi 2$ value 41.69 , d.f $=2, p<0.0001$ ). Lipid profile was above the standard cut-off for all risk assessing parameters. Conclusion: All recommended guide lines specially with respect to HOD complex demonstrates geo-cultural variation. There for it is pragmatic to test them for their suitability with reference to local population.
\end{abstract}

Keywords: HOD complex, Anthropometric variables, Geo-cultural population.

\section{Introduction}

Diabetes, hypertension, and dyslipidemia have been identified as major risk factors for Cardio Vascular Disease (CVD). It has been well documented that the Body Mass Index (BMI), waist and hip circumferences, and waist-to-hip ratio (WHR) are related to the risk factors for CVD. However, inconsistencies have been reported. Waist circumference had a stronger correlation with risk factors for CVD in Europeans, and in practice was a more reliable measurement than WHR. Welborn et al suggested that WHR is a better predictor of coronary heart disease and CVD mortality than waist circumference and BMI in an Australian population. WHR was identified as a dominant cardiovascular risk factor in Swedish populations. Waist circumference or WHR thus appear to be the most frequently used measures to identify individuals at risk of CVD and diabetes in large epidemiological studies. The results derived from populations of European descent may not be applicable to other populations. Wang et al observed that waist circumference was the best predictor for the risk of CVD and type 2 diabetes in an indigenous Australian population. $^{4}$

There is still ambiguity about the use of various anthropometric measures among Asians to predict risks of cardiometabolic diseases in patients suffering from diabetes and hypertension. There is an urgent need to evolve methods of secondary prevention in these populations to save the community from the burden of their complications. There is compelling evidence that indicates that maintenance of ideal BMI by lifestyle modifications helps in controlling the diseases and delaying their complications. Since universal cut off values do not hold good, identification of normal cut off values in each population is the primary step. Because upper body adiposity is also an important risk indicator for insulin resistance, the cutoff values for WC and WHR have also been determined for Asian Indians. There are various anthropometric parameters that suggest the risk of developing complications. This has created confusion among clinicians, so this study is being proposed to establish the best anthropometric measures in hypertensives and diabetics with special reference to Indian rural populations.

\section{Aim}

The study aimed at estimating the best associated and correlated anthropometric measurements with cardiometabolic risk from available surrogates and had the following objectives in mind:

1. To measure BMI, WC, and WHR in diabetic and hypertensive patients with and without complications having Blood reports (FBG and Lipid Profile)

2. To estimate the strength of association among anthropometric variables and the disease conditions.

3. To find the correlations of different surrogate anthropometric variables with cardiometabolic risk of disease conditions in the study.

4. To comment on the quality of different anthropometries with respect to Cardiometabolic risk estimation.

\section{Materials and Methods}

Cross-sectional study was carried out to determine the best anthropometric variable in Diabetes and Hypertensive subjects in rural central India with 200 inpatients over 3 months time with due permission from IEC(institutional Ethical Committee). 


\section{Inclusion Criteria}

All wilful consenting diabetic and hypertensive patients with and without complications with available Fasting Blood Glucose and Serum Lipid Profile report admitted to different wards of PRH in the age range of 45-65 years.

\section{Exclusion Criteria}

In-patients suffering from Type $1 \mathrm{DM}$ and Secondary hypertension with pregnancy-induced hypertension, gestational diabetes, and in Moribund and bedridden conditions were kept out of the study.

\section{Data Collection and Analysis}

Information's relating to study was collected in semistructured questionnaire from participants admitted to different wards over the study period. Standard procedure was adopted in measuring anthropometric and biochemical variables. Asian gender specific cut-offs were adopted for anthropometric measurements (Table 1). ${ }^{5}$ Information was coded and entered to SPSS 20 matrix. Descriptive and inferential analysis was carried out and reported in standard line keeping the nature of data in mind.

Table 1: Cut-off values for anthropometric measurements

\begin{tabular}{|l|c|c|}
\hline \multicolumn{1}{|c|}{ Criteria* } & Asian Males & Asian Females \\
\hline Cut off BMI & $>23 \mathrm{Kg} / \mathrm{M}^{2}$ & $>23 \mathrm{Kg} / \mathrm{M}^{2}$ \\
\hline Cut off WHR & 0.88 & 0.81 \\
\hline Cut off WC & $85 \mathrm{~cm}$ & $80 \mathrm{~cm}$ \\
\hline
\end{tabular}

\section{Results}

The gender based anthropometric profile of study participants in terms of number and $\%$ is presented in table 2.

Table 2: Anthropometric profile of study participants

\begin{tabular}{|c|c|c|}
\hline \multirow[t]{2}{*}{ Criteria } & \multicolumn{2}{|c|}{ Gender } \\
\hline & Male (\%) & Female (\%) \\
\hline \multicolumn{3}{|l|}{ BMI } \\
\hline Under nourished & $5(8 \%)$ & $0(0 \%)$ \\
\hline Normal & $9(14 \%)$ & $27(40 \%)$ \\
\hline Obese & $48(78 \%)$ & $41(60 \%)$ \\
\hline Total & $62(100 \%)$ & $68(100 \%)$ \\
\hline \multicolumn{3}{|c|}{ Waist Circumference } \\
\hline Obese & $25(40 \%)$ & $39(57 \%)$ \\
\hline Non obese & $37(60 \%)$ & $29(43 \%)$ \\
\hline Total & $62(100 \%)$ & $68(100 \%)$ \\
\hline \multicolumn{3}{|l|}{ Waist hip ratio } \\
\hline Obese & $45(73 \%)$ & $60(88 \%)$ \\
\hline Non obese & $17(27 \%)$ & $8(12 \%)$ \\
\hline Total & $62(100 \%)$ & $68(100 \%)$ \\
\hline
\end{tabular}

Descriptive presentation of abnormal blood lipid profile of participants like total cholesterol $>200 \mathrm{mg} / \mathrm{dl}(>5.2$ $\mathrm{mmol} / \mathrm{L})$, LDL-cholesterol $>130 \mathrm{mg} / \mathrm{dl}(>3.36 \mathrm{mmol} / \mathrm{L})$, HDL-Cholesterol $<60 \mathrm{mg} / \mathrm{dl}(<1.15 \mathrm{mmol} / \mathrm{L})$, Triglycerides $>160 \mathrm{mg} / \mathrm{dl}(>1.8 \mathrm{mmol} / \mathrm{L})$, and $\mathrm{VLDL}>40 \mathrm{mg} / \mathrm{dl}$ are presented in table 3 .
Table 3: Blood lipid profile of high risk patients/patients (with values greater than the cut off)

\begin{tabular}{|l|c|c|c|}
\hline $\begin{array}{c}\text { Blood lipid profile } \\
\text { cut off values) }\end{array}$ & Male & Female & Total \\
\hline Triglyceride & $11(39 \%)$ & $17(61 \%)$ & $28(100 \%)$ \\
\hline LDL & $4(20 \%)$ & $16(80 \%)$ & $20(100 \%)$ \\
\hline VLDL & $7(39 \%)$ & $11(61 \%)$ & $18(100 \%)$ \\
\hline HDL & $49(46 \%)$ & $57(54 \%)$ & $106(100 \%)$ \\
\hline Total cholesterol & $10(36 \%)$ & $18(64 \%)$ & $28(100 \%)$ \\
\hline
\end{tabular}

In terms of overweight and obesity it was observed that $53(41 \%)$ of the overweight and obese were diabetic and $30(23 \%)$ of non obese were diabetic. But Fischer's exact test value (P value 0.169) showed statistical nonsignificance. Whereas highly significant association was observed between BMI and hypertension $\left(\mathrm{X}^{2}=0.0034\right.$ d.f $=1, \mathrm{P}<0.001)$. Here it was observed that $68(52 \%)$ of hypertensives were overweight or obese while only $21(16 \%)$ were of Non hypertensives type. (Table 4)

Table 4: Association between BMI and hypertension

\begin{tabular}{|l|c|c|c|}
\hline BMI $\left(\mathbf{K g} / \mathbf{m}^{2}\right)$ & Hypertensive & $\begin{array}{c}\text { Non } \\
\text { Hypertensive }\end{array}$ & Total \\
\hline Non Obese & $20(15 \%)$ & $21(16 \%)$ & $41(32 \%)$ \\
\hline $\begin{array}{l}\text { Overweight }+ \\
\text { Obese }\end{array}$ & $68(52 \%)$ & $21(16 \%)$ & $89(68 \%)$ \\
\hline Total & $88(67 \%)$ & $42(32 \%)$ & $130(100 \%)$ \\
\hline
\end{tabular}

Association between waist circumference and Diabetes in male and female participants with respective cut-off values at $\mathrm{WC}>85 \mathrm{~cm}$ and $\mathrm{WC} \geq 80 \mathrm{~cm}$ reported statistical non-significance $(\chi 2$ yates correction $=0.02167$ d.f $=1$ $\mathrm{p}=0.88$ ) and Fischer's Exact test, $\mathrm{p}=0.06$ respectively. But we observed a valid statistical association for waist Circumference and Hypertension in both the gender. (Table 5)

Table 5: Association between waist circumference and hypertension in males and females

\begin{tabular}{|l|c|c|c|}
\hline $\begin{array}{c}\text { Waist } \\
\text { Circumference }\end{array}$ & Hypertensive & $\begin{array}{c}\text { Non- } \\
\text { Hypertensive }\end{array}$ & Total \\
\hline WC (Male) $\geq 85$ & $22(35 \%)$ & $3(5 \%)$ & $25(40 \%)$ \\
\hline WC (male) $\leq 84$ & $22(35 \%)$ & $15(25 \%)$ & $37(60 \%)$ \\
\hline Total & $42(68 \%)$ & $18(30 \%)$ & $62(100 \%)$ \\
\hline WC (Female) $\geq 80$ & $21(31 \%)$ & $18(26 \%)$ & $39(57 \%)$ \\
\hline WC (Female) $\leq 79$ & $24(34 \%)$ & $6(9 \%)$ & $29(43 \%)$ \\
\hline Total & $45(65 \%)$ & $14(35 \%)$ & $68(100 \%)$ \\
\hline
\end{tabular}

*Fischer's Exact test, $\mathrm{p}=0.02$ Significant for males ** $\chi^{2}$ Yates correction $4.025, \mathrm{p}<0.05$ for females

The result showed no statistical association for type 2 diabetes with waist hip ratio with respect to the reference cut-off for both the gender. For males Fisher's exact test reports $\mathrm{p}=1$ and for females Fischer's Exact test, $\mathrm{p}$ value was 0.06 but presence of positive family history was very strong among diabetic participants $\left(\chi^{2}\right.$ value 8.47 d.f $=1$ $\mathrm{p}=0.003)$. 
Table 6: Association between diabetes, hypertension, smoking, alcohol, diet, and exercise

\begin{tabular}{|l|c|c|c|c|}
\hline \multicolumn{1}{|c|}{ Criteria } & Diabetes & Hypertension & $\begin{array}{c}\text { Diabetes+ } \\
\text { Hypertension }\end{array}$ & Total \\
\hline Smoking & $3(6 \%)$ & $21(43 \%)$ & $25(51 \%)$ & $49(100 \%)$ \\
\hline Alcohol & $15(25 \%)$ & $21(34 \%)$ & $25(41 \%)$ & $61(100 \%)$ \\
\hline Smoking+ alcohol & $15(29 \%)$ & $14(27 \%)$ & $23(44 \%)$ & $52(100 \%)$ \\
\hline Diet & $35(38 \%)$ & $21(24 \%)$ & $35(38 \%)$ & $91(100 \%)$ \\
\hline Exercise & $24(57 \%)$ & 0 & $23(56 \%)$ & $47(100 \%)$ \\
\hline No exercise & $18(43 \%)$ & $47(100 \%)$ & $18(44 \%)$ & $83(100 \%)$ \\
\hline Total & $42(100 \%)$ & $47(100 \%)$ & $41(100 \%)$ & $130(100 \%)$ \\
\hline
\end{tabular}

$* \chi 2$ value 41.69, d.f $=2, \mathrm{p}<0.0001$ for exercise group and $* * \chi 2$ value 18.472 d.f $=6 \mathrm{p}=0.0052$ for others.

Table 7: Lipid profile and anthropometric variables in studied population

\begin{tabular}{|c|c|c|c|c|}
\hline $\begin{array}{c}\text { Total } \\
\text { participants }\end{array}$ & Cholesterol & $\mathrm{BMI}>23$ & BMI $<23$ & Total \\
\hline & Triglycerides & $23(82 \%)$ & $5(18 \%)$ & $28(100 \%)$ \\
\hline & LDL & $14(70 \%)$ & $6(30 \%)$ & $20(100 \%)$ \\
\hline & VLDL & $16(89 \%)$ & $2(11 \%)$ & $18(100 \%)$ \\
\hline & Decreased HDL & $72(68 \%)$ & $34(32 \%)$ & $106(100 \%)$ \\
\hline & Total Cholesterol & $16(57 \%)$ & $12(43 \%)$ & $28(100 \%)$ \\
\hline \multirow[t]{6}{*}{ Males } & Cholesterol & $\mathrm{WC}>85 \mathrm{~cm}$ & $\mathrm{WC}<85 \mathrm{~cm}$ & Total \\
\hline & Triglycerides & $5(45 \%)$ & $6(55 \%)$ & $11(100 \%)$ \\
\hline & LDL & $4(100 \%)$ & 0 & $4(100 \%)$ \\
\hline & VLDL & $1(14 \%)$ & $6(86 \%)$ & $7(100 \%)$ \\
\hline & Decreased HDL & $16(34 \%)$ & $31(64 \%)$ & $47(100 \%)$ \\
\hline & $\begin{array}{c}\text { Total } \\
\text { cholesterol }\end{array}$ & $15(100 \%)$ & $0(100 \%)$ & $15(100 \%)$ \\
\hline \multirow[t]{6}{*}{ Females } & Cholesterol & $\mathrm{WC}>80$ & $\mathrm{WC}<80$ & Total \\
\hline & Triglycerides & $15(88 \%)$ & $2(12 \%)$ & $17(100 \%)$ \\
\hline & LDL & $11(69 \%)$ & $5(31 \%)$ & $16(100 \%)$ \\
\hline & VLDL & $9(82 \%)$ & $2(18 \%)$ & $11(100 \%)$ \\
\hline & Decreased HDL & $33(58 \%)$ & $24(42 \%)$ & $57(100 \%)$ \\
\hline & Total cholesterol & $28(80 \%)$ & $7(20 \%)$ & $35(100 \%)$ \\
\hline \multirow[t]{6}{*}{ Males } & Cholesterol & WHR $>0.88$ & WHR $<0.88$ & Total \\
\hline & Triglycerides & $8(73 \%)$ & $3(27 \%)$ & $11(100 \%)$ \\
\hline & LDL & $4(100 \%)$ & 0 & $49(100 \%)$ \\
\hline & VLDL & $1(14 \%)$ & $6(86 \%)$ & $7(100 \%)$ \\
\hline & Decreased HDL & $33(67 \%)$ & $16(33 \%)$ & $49(1005)$ \\
\hline & Total cholesterol & $10(100 \%)$ & 0 & $10(100 \%)$ \\
\hline \multirow[t]{6}{*}{ Females } & Cholesterol & WHR $>0.81$ & WHR <0.81 & Total \\
\hline & Triglycerides & $16(100 \%)$ & 0 & $16(100 \%)$ \\
\hline & LDL & $16(100 \%)$ & 0 & $16(100 \%)$ \\
\hline & VLDL & $11(100 \%)$ & 0 & $11(100 \%)$ \\
\hline & Decreased HDL & $51(89 \%)$ & $6(11 \%)$ & $57(100 \%)$ \\
\hline & Total cholesterol & $16(89 \%)$ & $2(11 \%)$ & $18(100 \%)$ \\
\hline
\end{tabular}

On analysis to find any association between diabetes, hypertension, smoking, alcohol and dietary and exercise habits a very strong association was noticed $(\mathrm{p}<0.001)$. Table 6 represents these findings.

Description of lipid profile with respect to different anthropometric variables in the studied population is presented in table on 7. It was evident that risk cut-off for anthropometric variables also recorded lipid profiles on higher side.
On two tailed Pearson Correlation Significance analysis for the total 130 participants BMI reported very strong positive correlations with WC $(\mathrm{r}=0.588, \mathrm{p}=0.000)$, but negative one with FBS level $\left(\mathrm{r}=-.235^{* *}, \mathrm{p}=.007\right)$. WC was positively correlated with WHR $\left(\mathrm{r}=.593^{* *}, \mathrm{p}-.000\right)$, and BMI. FBS was negatively related to BMI, systolic blood pressure $\left(\mathrm{r}=-.332^{* *}, \mathrm{p}-000\right)$ and diastolic blood pressure $(\mathrm{r}=-$ $.232^{* *}$, p- 008). Systolic blood pressure had negative relationship with FBS but positive one with diastolic blood pressure $\left(\mathrm{r}=.766^{* *}, \mathrm{p}-.000\right)$. 


\section{Discussion}

130 inpatients from different wards were studied in accordance with the aim and objectives. An effort was made to estimate the best associated and correlated anthropometric measurements with respect to cardiometabolic risk.

Established anthropometric tools were compared for their underlined associations and co-relationships with respect to diseases in question.

Essential HTN was found to be associated with BMI and WC but negatively correlated to FBS. Association of HTN with WC was reported in an Australian aborigine population. $^{2}$ Differing results with respect to HTN, BMI, WC and WHR are reported by different researchers thereby asking for development of geo-cultural tools for better assessment and management of HOD complex. ${ }^{4-8}$

Type $2 \mathrm{DM}$ was found to be positively associated with family history of the disease and statistical association with BMI, WC, and WHR could not be established. Genetic concordance as a strong risk indicator is proved time and again. ${ }^{9}$

Type 2DM, essential HTN and co presence of both of the conditions were positively associated with vices like smoking, alcohol consumption, combination of these two habits, risk enhancing diet, and lack of exercises. Impact of risky habits on 'HOD complex' is not new to present day researchers. ${ }^{10}$

Cardio-metabolic risk assessment in terms of above normal (cut-off) lipid profiles showed higher levels with respect to all studied anthropometry and both gender. Though their significance could not be statistically established but it remains a proven fact at global level. ${ }^{7-10,12}$

WC and BMI were found closer associates for essential HTN in the concluded study thereby strengthening the call for more geo-cultural exploration and establishing locally valid standards rather than blind following recommendations from diverse arbitrations. ${ }^{1,4-7}$

\section{Conclusion}

Before generalizing any guidelines an attempt must be made to find its suitability form local context. Though there are different surrogate guidelines as proxy risk indicators for type2DM, essential HTN and the consequent cardiometabolic risk assessment are in place, its practicality should be questioned and if needed adequacy established from local context. The concluded study stressed on this for local rural citizens from central India and is of the opinion that BMI and WC are better anthropometric measures for study of essential HTN. Positive family history for type $2 \mathrm{DM}$ is a reliable associate for that condition. Lipid profile above the recommended cut-offs showed higher prevalence in patients with reporting anthropometric risks.

\section{Conflict of Interest: None.}

\section{References}

1. Sinha N.D, Mishra B.N, Mohapatra S C. Comprehending hypertension by 'comprehensive rules of thirds and halves'. $J$ Community Health Manag 2017;4(4):133-7.

2. Mishra B, Sinha ND, Gidwani H, Shukla SK, Kawatra A, Mehta S C. Equipment errors: A prevalent cause for fallacy in blood pressure recording - A point prevalence estimate from an Indian health university. Indian J Community Med 2013;38:1521.

3. Mishra B, Sinha ND, Ur Rehman H. Quantifying variation in blood pressure measurement through different arm cuffs and estimating its impact on diagnosis of hypertension at community level. J Health Res Rev 2017;4:71-7.

4. Snijder MB, Zimmet PZ, Visser PZ: The Australian Diabetic Study. Int J Obes 2004

5. Textbook of Pathology- Harshmohan. $5^{\text {th }}$ edition, 2005. Publishers- Jaypee Brothers, New Delhi. Appendix: Normal Values, page no:-944.

6. Pouliot MC, Despres JP. Waist Circumference and abdominal sagittal diameter: best simple anthropometric indexes of abdominal visceral adipose tissue accumulation and related cardiovascular risk in men and women. Am J Cardiol 1994;73:460-8.

7. Welborn TA, Dhaliwal SS, Bennett SA. Waist-Hip ratio is the dominant risk factor predicting cardiovascular death in Australia. Med J Aust 2003;179:580-5.

8. Chiruzu Nishida. Appropriate BMI for Asian populations and its implications for policy and intervention strategies, Lancet 2004;363(9403):157-63.

9. Zaki Morad Mohd Zaher. Optimal Cut-off levels to define obesity: body mass index and waist circumference, and their relationship to cardiovascular disease, dyslipidemia, hypertension and diabetes in Malaysia. Asia Pac J Clin Nutr 2009;18(2):209-16.

10. Wang Z, Hoy WE. Body size measurements as predictors of type II diabetes in Aboriginal people. Int J Obes 2004;28:1580-4.

11. Chamkuttan Snehalata, Diabetes Research Centre, Chennai, India: Diabetes Care 2003;26(5):1380-4.

12. Park's Textbook of Preventive and Social Medicine. $20^{\text {th }}$ edition, 2009. Publisher Banarasidas Bhanot, Jabalpur. Chapter - Epidemiology of Chronic non-communicable diseases and conditions. Page no-323

How to cite this article: Sinha ND, Mishra BN, Mohapatra SC. Study of association and correlation of cardio-metabolic risk in diabetics and hypertensive patients with established anthropometric surrogate. J Community Health Manag 2019;6(1):21-4. 